\title{
Analyze Traders' Types and Their Behavior In the Saudi Stock Market and its Impact on Their Reactions To the Movement of Stock Prices"
}

\author{
Dr. Sahar M. Mahran \\ Business Administration Department \\ Faculty of Commerce \\ Ain Shames University, Egypt \\ Financial Department \\ Faculty of Economics \& Administration \\ King Abdullaziz Univirsity, Jeddah, KSA
}

\begin{abstract}
:
This research aims to analyze trader's types and their behavior in the Saudi stock market. The study classifies traders to identify the structural component of the stock market and to test the significant of difference in their behavior and their reactions to the movement of stock prices. One Way ANOVA analysis used to demonstrate significant differences among the traders' behavior according to price variability, facing loss and trust in specific stock. The results described that $60 \%$ of the total traders in the sample are investors, while the percentage of speculators are $40 \%$, this help to analyze and interpret the impact of this distribution relative on the share trading in the Saudi stock market. On the other hand, the results shown that there are significant differences among their behavior towards price rise or reduction, as well as their reactions towards facing loss. Also there are significant correlation between the types of traders and their reactions to the share prices movements. In addition, the results indicate to increase the ratio of traders who face loss. Since traders ratio that face loss is (86\%), while the ratio of traders that not face loss is (14\%). Meanwhile there is no significant difference between their behavior when they believe (trust) of stock and expect to achieve more of it.
\end{abstract}

\section{Introduction:}

Trading and prices in the stock market affected by the awareness of traders to price movement and their response (whether it was positive or negative). Consequently, this research aims to analyze the types of traders and their behavior in the Saudi stock market as one of the recently emerging financial markets (as an example of developing countries). Throughout market survey for random sample of traders to characterize the relative structure of traders represent the market components, analyze their behavior and reactions to the movement of prices either rise or fall. The results contribute to interpret the trader's behavior in the market and their response to the price trends. In addition, analyzing the reactions of different types of traders in the market, that helps the market participants (whether individuals or institutions) in building their expectations and raise their ability to make proper and efficient decisions.

\footnotetext{
* This Research Was Submitted in April 2011, and Accepted for Publishing in Sept. 2011.
} 


\section{Literature Review:}

The universal features of asset market seem to originate from the trading activity of their market participants. Many studies contribute in these areas such as those mentioned by Kirman (1991) and Brock,et al.(2000) provide a realistic description of traders' behavior. Their models were able to replicate the main properties of asset price dynamics.

Meanwhile, Heemeijer, et al. (2009) estimate individual forecasting rules and investigate how these explain the differences in aggregate market outcomes, since market behavior depends to a large extent on whether realized market prices respond positively or negatively to average price expectations. In the case of negative expectations feedback, as in commodity markets, prices converge quickly to their equilibrium value, confirming the rational expectations hypothesis. In the case of positive expectations feedback, as is typical for speculative asset markets, large fluctuations in realized prices and persistent deviations from the benchmark fundamental price are likely.

Also Hales (2009) examined how individual trading behavior varies across treatments and time. They mentioned that any differences in individual trading aggressiveness would translate into differences in observed trading volume in the markets. The results shown that, traders who prompted to estimate signal disagreement will submit less aggressive orders than traders who prompted to estimate security value. In addition, they found that trading behavior would qualified by an ordinal interaction between prompt and market transparency. Meanwhile, trading aggressiveness will be highest in markets where the order book is closed and traders prompted to estimate security value.

Added to that Daniel, et al. (2002) investigated the evidence of how imperfect rationality affects trading, expectations and prices in capital markets. They found several recent surveys summarize evidence about psychology of the individual and its relevance for financial and other economists.

The results of Lee and other (2002) showed that sentiment is a systematic risk that is priced. Excess returns positively correlated with shifts in sentiment. Moreover, the magnitude of bullish changes in sentiment leads to downward (upward) revisions in volatility and higher (lower) future excess returns.

On the other hand, David and Teoh (2002) have argued that there is now persuasive evidence that investors make major systematic errors. The evidence is persuasive that psychological biases affect investor behavior and market prices substantially. Furthermore, there are some indications that as result of mispricing there is substantial misallocation of resources in the economy.

Brown et al. (2002) found some support for the influence of Chinese culture and superstition on year-round number preferences of traders, but it is located solely in the Hong Kong market, the even numbers increases with the stock's price level and decreases with the precision with which price is known.

Caginalp and Ilievab (2008) studied the dynamics of trader motivations in asset bubbles and analyzed asset market experiments by distinguishing participants who are net bidders versus net offers. When prices become above fundamental value, the evidence shows that the cash supply of the bidders diminishes and the cash supply of the offers increases as the bubble 
forms. This suggests that the cash of the momentum players fuels the bubble and inadequate cash in their possession causes the reversal.

Other studies distinguish between investors such as Lee, et al (1999) who examined interdependencies among institutional investors, big individual investors and small individual investors. Also they studied the effects of their trading on stock returns at Taiwan Stock Exchange (TSE).The results imply that, during the sample period, shown that; big individual investors are the most well informed players; their trading affects not only stock returns but also small individual investors. Small individual investors are uninformed and are slow learners. Their orders to trade tend to provide liquidity to institutional and big individual investors, but there is no compensation for their liquidity services. In addition, institutional investors follow neither positive-feedback nor negative feedback trading strategies. Overall, the responses to shocks, except for those of small individual investors decay quickly, indicating that the TSE can absorb shocks quickly and evidently. This analysis implies that small individual investors would be better of institutionalizing their investment decisions.

Also Easley and O'Hara (1987) argue that the concept of informed traders wish to trade, they would prefer to trade large amounts at any given price.

Meanwhile, Barclay and Warner (1993) distinguish informed traders from noise traders by their choice of trade size. Medium to large trades were made by the informed, while small trades are more likely to be made by noise traders.

Ng, and Wu (2007) analyze the trading behavior of individual and institutional investors across Mainland China. The results showed that groups of individual investors with varying trade values (as proxies for wealth levels) engage in different trading strategies. The results also indicate that a small group of wealthiest Chinese individuals tends to behave like institutions when they buy stocks, and behave like less wealthy individuals when they sell. Furthermore, only the trading activities of institutions and of wealthiest individuals can affect future stock volatility, but those of Chinese individual investors at large have no predictive power for future stock returns.

Also Ayers, et al. (2011) examine whether the two distinct post-earnings-announcement drifts associated with seasonal random-walk-based and analyst-based earnings surprises are attributable to the trading activities of distinct sets of investors. They predicted and found that small (large) traders continue to trade in the direction of seasonal random-walk-based (analystbased) earnings surprises after earnings announcements. They also found that when small (large) traders react more thoroughly too seasonal random-walk-(analyst-) based earnings surprises at the earnings announcements, the respective drift attenuates. Further evidence suggests that delayed small trades associated with random-walk-based surprises are consistent with small traders' failure to understand time-series properties of earnings, whereas delayed large trades associated with analyst-based surprises are more consistent with a longer price discovery process. They also found that the analyst-based drift has declined in recent years.

Other studies classified traders into Speculative noise trading and manipulation.

For example, Vitale (2000) explored that in the foreign exchange market, uninformed speculators find it convenient to trade on noise for gain an informational advantage. he analyze the trade-off between the cost of the "informational investment" and the profits this 
brings about, studying the optimal manipulation strategy under different hypotheses on the activity of market participants. These results give a possible explanation for the presence of noise trading in the foreign exchange market While

Carcano, et al. (2005) where they tried to determine sufficient conditions for the parameters of a mean reverting price process as a function of transaction costs, to allow a speculative trader to have positive expectations when deciding to take a position. They estimate the mean reverting parameters for some commodities and correct them for transaction costs to assess whether the potential inefficiency is actually relevant for speculative purposes. Speculative strategies devised to earn excess returns from such price processes. Actually, the gain opportunities of mean reversion should correct to account for transaction costs.

Dibeh (2005) investigated the effect of time delays in the chartists expectations function on the deviation of asset prices from their fundamental value. A nonlinear model shown that limit cycles may exist explaining the persistence of these deviations speculative markets. Time delays showed an effect on the generation of limit cycles. The model also extended to include endogenous wealth dynamics. Solutions to the model show that time delays affect the time evolution of the chartists and fundamentalists share of wealth.

The factors affecting stock market traders decisions been studied by $\mathbf{F o n g}(\mathbf{2 0 0 9})$ where they found that liquidity, The higher turnover rate of shares and information asymmetry as important factors in explaining why some firms have higher A-share premiums than others and why investors remain attracted to this market compared to the other.

Hales (2009) investigated if investors willing to agree to disagree and how to disagreement and attention to disagreement affect trading behavior. He found that traders are generally insensitive to adverse selection and readily engage in suboptimal, speculative trade. Moreover, this effect does not decline across trials suggesting that market feedback alone is unlikely to correct traders' behavior. In contrast, when traders are prompted to assess disagreement over asset values or when they trade in more transparent markets, they appear less willing to 'agree to disagree "these results provide insight into why investors depart from rational trading strategies and how investors' psychology will influence trading behavior.

Odean (1998) shown that the individual investors trading through a large discount brokerage firm tend to be more likely to sell their winners than their losers. Moreover, he shown that the stocks that investors choose to sell subsequently outperform the stocks that investors retain. A substantial amount of the underperformance of the losers relative to the winners derives from the momentum effect, but momentum does not appear to explain all of the underperformance of these investors. Interestingly, the individual investor behavior that Odeon observes goes against the investing maxim: "ride your winners and sell your losers". The investing maxim may be designed as a corrective to individual biases. An open question is who is taking the opposite side of these individual investors' transactions. Also, more work is needed to complement the work on individual sales of stocks examining what forces cause individual investors to purchase common stocks. One relevant datum is that there are large flows into mutual funds, which have experienced good past performance. Home sellers also appear to be loss-averse in the way that they set prices. Their reluctance to sell at a loss relative to past purchase price helps explain the strong positive correlation of volume with price movements 
Investors use past performance as an indicator of future performance in mutual fund and stock purchase decisions this concept was been study by Sirri and Tufano (1998) who provide evidence that flows into mutual funds are concentrated among those funds which have had extraordinarily high performance. This evidence suggests that investors are naively extrapolating past mutual fund success, when empirical evidence suggests that there is little or no persistence in performance.

Also Nelson, et al. (2001) reported two experiments that demonstrate how information strength and weight affect confidence, trading, prices, and wealth in laboratory markets. Their results indicate that information strength and weight affect individual over- and under confidence and that, market participants lack sufficient self-insight to avoid trading when they are biased. Therefore, market prices are biased, and market participants with high-strength, low-weight information systematically transfer wealth to participants with low-strength, highweight information.

Also Narayan, et al. (2011) tests the share price clustering phenomena and its determinants for the Mexican share market. They consider the top-12 listed companies. They observe cases of significant price clustering behavior in the Mexican share market. Their analysis of the determinants of price clustering reveals that volume and volatility negatively affect price clustering, consistent with theory. However, price has a negative effect on price clustering. While this is inconsistent with theory, it implies that in Mexico market participants are concerned about finer partitions of price.

The results of Kaustia, Torstila (2011) are consistent with the idea that personal values are a factor in important investment decisions, in this case leading to stock market aversion. The results are inconsistent with alternative explanations such as wealth effects, risk aversion, reverse causality, return expectations, or social capital.

In addition to Alsubaiea and Najandb (2009) test the effect of trading volume on the persistence of the time-varying conditional volatility of returns in the Saudi stock market. They use two different proxies for information arrival, intra-day volatility, and overnight indicators. They find that these are good proxies for information and are important as contemporaneous volume in explaining conditional volatility.

Burks (2011) looks for evidence of investor confusion by examining stock returns and trading volume. This study found that the initial price reaction to restatement announcements becomes significantly less negative after Sarbanes-Oxley Act (SOX), even after controlling for the less egregious nature of post- (SOX) restatements. He tests whether stock prices drift negatively over the months and years after the initial reaction. He found no evidence of statistically negative drifts unique to the post-SOX period. In fact, post-SOX drifts are statistically less negative than pre-SOX drift suggesting that price efficiency actually improves after SOX.

\section{Methodology:}

This study analyzes Trading Behavior of four types of traders in Saudi stock market by classifying traders into big versus small traders and Speculative versus Investor, the random sample has been selected. The difficulties were due to lack of information about the market traders' community of the current research and their relative distribution. Therefore, stratified 
random sample could not selected, so this study was relying on the flexible random sample , which were classified traders to four types, especially one of the objectives of this research is to analyze the structure relative of traders types in the Saudi stock market

\section{Top of Form}

Statistical formula used to determine the appropriate sample size is ${ }^{(1)}$ :

$$
\mathbf{N}=\mathbf{P Q}(\mathrm{Z}) \mathbf{2} / \mathrm{E} 2
$$

Where: N: sample size

P: The proportion of the community to be studied in case of lack of knowledge that ratio is $(50 \%)$, uses the largest possible proportion,

Q Percentage complementary

Z: class standard (At the level of significance $0.05=1.96 \& 0.01=2.58$ )

E at both sampling error (0.05 or 0.01$)$

When assuming the proportion of available community (50\%), and the complementary percentage (50\%), and standard-class (1.96) and 0.05 sampling error, the sample size is (384) the individual and this volume represents a society.

Another way to determine the appropriate sample size

$$
\mathrm{N}=\mathbf{4 p Q} / 25
$$

As the sample size $\mathrm{N}$ and probability value ranging from (30 to 60), $\mathrm{Q}=100-\mathrm{P}$

When the 336 people and bringing the sample size $\mathrm{Q}=70, \mathrm{P}=30$

$\mathrm{Q}=50, \mathrm{P}=50$ and becomes the sample size (400) individual

Therefore, the number of questionnaires that have been distributed were 500 to get the required number of sample size but only350 of them could be obtained, and 269 of them have a completed answer.

The sampling unit: Mainly the questionnaire was distributed individually (small or big traders).This study Not adopted the classification of traders based on the individuals and institutions, but the classification that used depend on the size of the investment by the traders and their goal from trading. Therefore, in this study traders subdivided into investor or Speculative based on two criterions. The first one is their goals (objectives), since the investors seek to achieve stable and continue gains. While Speculative traders seek to achieve high and quickly gains, The second is the period that they keep stock. Since Speculative traders keep the stock for a short period as soon as the expected event- taking place. While investors traders kept the stock for period longer than Speculative traders. Consequently Question number (1) and number (2) use to classify the traders into investor or Speculative.

(1) Alsiaad Jalal and Jalal, Mostafa. (1990). Introduction to statistical sampling methods, Jeddah, Library Misbah , pp 110-121 
Investors tend to achieve stable and continue gains, but Speculative traders tend to achieve high and quickly gains throw short period. Also individual investors subdivided into big and small individual investors based on their trade sizes. Lee et al. (1999) use 10,000 shares as the dividing point for the following reasons. First, the budget constraints of small investors imply that their trades are likely to be small. Second, trades of 10,000 shares or more commonly defined as big trades. So Question number (3) use to classify the traders into small or big category

Consequently this study examines four types of traders as followed in table (1).

Table (1)

Types of traders

\begin{tabular}{l|l|l}
\hline \hline Stock market Traders & Small & Big \\
\hline Speculative & small Speculative (SS) & Big Speculative (BS) \\
\hline Investor & small Investor (SI) & Big Investor (BI) \\
\hline \hline
\end{tabular}

This study used ONE-Way- ANOVA as statistical approach to analyze the trading behavior of big versus small traders (based on their wealth levels). Also Speculative versus Investors (based on their targets). Therefore, the null hypothesis assuming there is no significant differences between the behavior of four mentioned types of traders in the market toward either (price trend to high or down). Added to test their feedback toward facing loss. While alternative hypothesis is that they different.

Questions from 4 - 8are related to the trading behavior of four types of traders engage in either a positive feedback (when price trend to rise) or a negative-feedback (when price trend to reduction), trading reaction toward facing loss and effect of their believing (trust) toward specific stock forecast.

\section{Data Analysis and Testing Hypotheses:}

The results had shown that trader's classification along the samples in this research as follows:
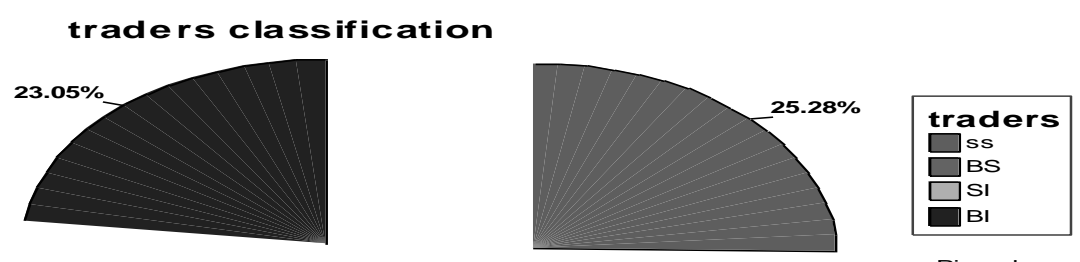

Pies show counts

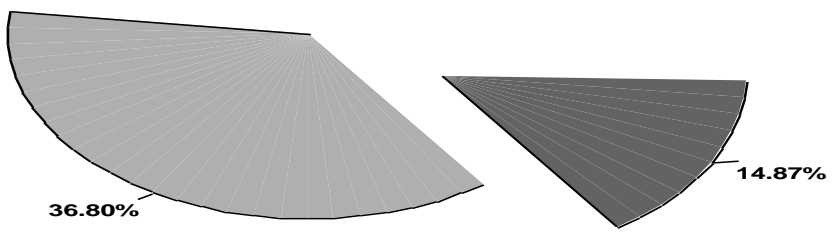

(Figure -1) Traders Classification along the Samples 
The results described from the previous figure that category of small investors represent $(37 \%)$ which is the largest part of the random sample, while the percentage of big investors $23 \%$, so $60 \%$ of the total sample traders in the Saudi stock market are investors. On the other hand, the percentage of big speculators $25 \%$ and small speculators, $15 \%$, so $40 \%$ of traders in the market are speculators. There is no doubt that this category of traders helps to:

1- Understand the structural component of traders in the Saudi stock market.

2- Analyze and interpret the impact of this structural on the stock trading in this market.

\section{Test of hypothesis:}

\section{First hypothesis:}

$\mathrm{H}_{0}$ - the null hypothesis assuming that:

There is no significant differences among the behaviors (and reactions) of traders (four types) in the market toward price movement (either trend to high or down), facing loss, and trusting in specific stock.

$\mathrm{H}_{1}$ - the alternative hypothesis:

They do have different reactions toward the mentioned events. (Their reactions will be in the same average weight change.)

Variables used in the test Variables are nonparametric that are included: - Types of traders (four types)-their Behavior and reactions to the movement of prices, facing loss, and trusting in specific stock.

By using One Way ANOVA, this study investigates the traders' behavior when they face price rise or reduction. Also test their reaction for loss and their believing of stock. Using variance analysis to demonstrate significant differences among the traders' behavior according to price variability, their reactions for facing loss and for trust in specific stock as shown in the table (2) as following:

Table (2)

The Results of ANOVA Test for Traders' Behavior

\begin{tabular}{ll|c|c|c|c|c}
\hline \hline & $\begin{array}{c}\text { Sum of } \\
\text { Square }\end{array}$ & df & $\begin{array}{c}\text { Mean } \\
\text { Square }\end{array}$ & F & Sig. \\
\hline \hline Price rise & Between Groups & 25.119 & 3 & 8.373 & 8.172 & .000 \\
& Within Groups & 271.521 & 265 & 1.025 & & \\
& Total & 296.639 & 268 & & & \\
\hline Price & Between Groups & 43.920 & 3 & 14.640 & 30.607 & .000 \\
reduction & Within Groups & 126.757 & 265 & .478 & & \\
& Total & 170.677 & 268 & & & \\
\hline Believing & Between Groups & .848 & 3 & .283 & .414 & .743 \\
& Within Groups & 180.892 & 265 & .683 & & \\
& Total & 181.720 & 268 & & & \\
\hline Action & Between Groups & 9.579 & 3 & 3.193 & 2.788 & .041 \\
& Within Groups & 303.558 & 265 & 1.146 & & \\
& Total & 313.138 & 268 & & & \\
\hline \hline
\end{tabular}


From table (2) the null hypothesis can be rejected (at Statistical Significance 5\%), the result shown that $\mathrm{p}$ - value is less than (.05). So there are significant differences among types of traders in the market according to price rise ( $\mathrm{p}$ - value $=.000$ ) or reduction ( $\mathrm{p}$ - value $=.000$ ). Also there are significant differences among types of traders in the market according to their behavior toward facing loss ( $\mathrm{p}$ - value $=.041$ ) which is shown in the following figure (2).

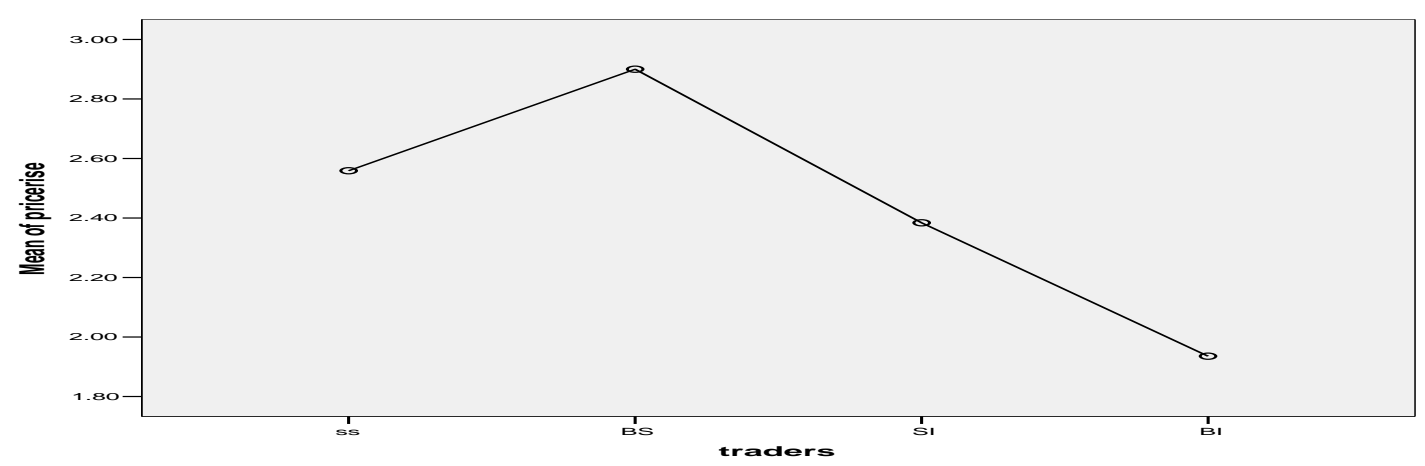

Price trend to rise

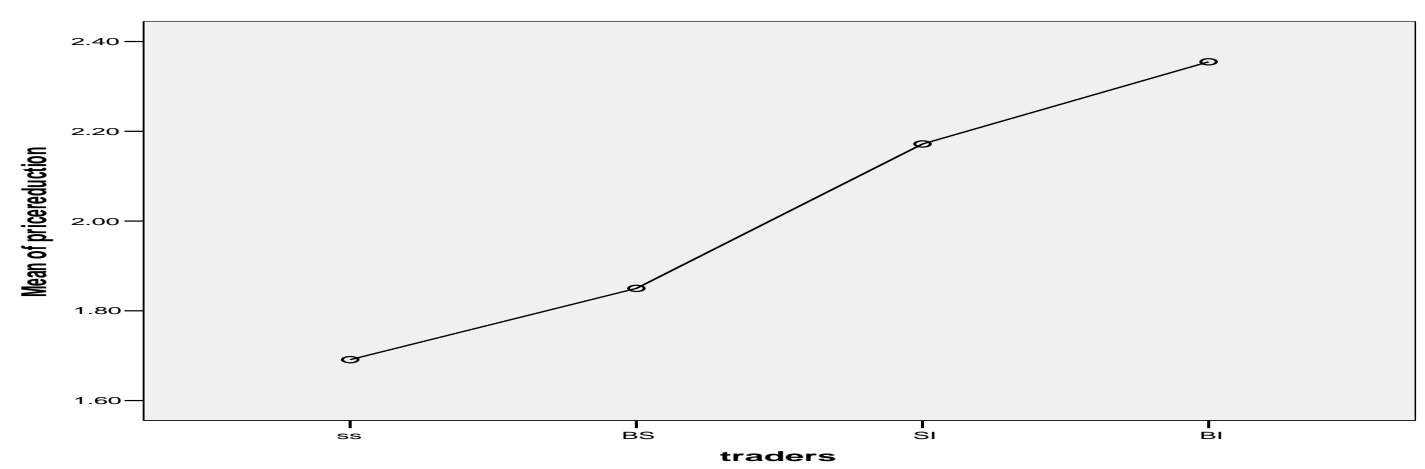

Price Trend to Reduction

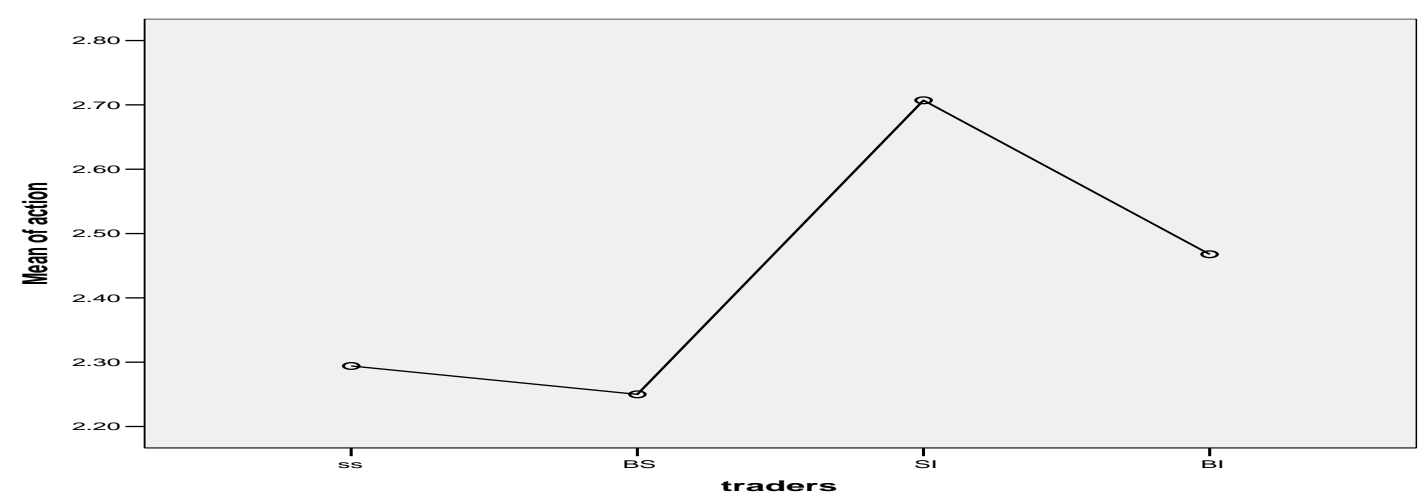

Reactions toward Facing Loss

Figure (2) Test the Significant Differences among Types of Traders 
Figure (2) is a plot of traders' behavior according to prices variability's and their reactions toward facing loss. This Figure proves that the null hypothesis can be rejected. Therefore, there is no relationship between the variability of four traders' reaction and the variability's in price or variability of facing loss. Therefore the mean difference is significant at Statistical Significance 5\%. While there is no variability among traders' behavior when they trust with a specific share ( $\mathrm{p}$-value $=.743>.05$ ), so the null hypothesis can be accepted.

Based on the results of variance analysis test, the comparisons between the averages have been done by using Least Significance Difference (LSD). The results shown that in the case of price rise there are significant differences between big investors and small investors, while in the case of a price reduction there are significant differences between the behavior of speculators (whether small or big ) and both the small and big investors. Also in the case of the face loss, there was a significant difference between the behavior of speculators (whether small or big) and the small or big investors.

This study tests the correlation between the type of traders and their reactions to the movements of stock prices as following:

\section{The second hypothesis:}

$\mathrm{H}_{0}$ - there is no correlation between the type of traders and their reactions to the movements of prices (Sig of Chi square $>$. 05) $\mathrm{H}_{1-}$ (Sig of Chi square <. 05)

The results in case of prices rise:

Table (3)

Types of traders and their reactions to price rise

\begin{tabular}{|c|c|c|c|c|c|c|c|c|c|c|c|}
\hline \multirow[b]{2}{*}{ Trades } & \multicolumn{2}{|c|}{ Buy More } & \multicolumn{2}{|c|}{$\begin{array}{l}\text { Keeping the } \\
\text { Stock }\end{array}$} & \multicolumn{2}{|c|}{ Sell Quickly } & \multicolumn{2}{|c|}{$\begin{array}{l}\text { Wait until } \\
\text { Highest Price }\end{array}$} & \multicolumn{2}{|c|}{ Total } & \multirow{2}{*}{\begin{tabular}{|c|}
$\begin{array}{c}\text { Sig of Chi- } \\
\text { Square } \\
\text { Test }\end{array}$ \\
.000 \\
\end{tabular}} \\
\hline & Frequency & $\%$ & Frequency & $\%$ & Frequency & $\%$ & Frequency & $\%$ & Frequency & $\%$ & \\
\hline SS & 11 & $17 \%$ & 5 & $7 \%$ & 30 & $44 \%$ & 22 & $32 \%$ & 68 & & \\
\hline BS & 5 & $13 \%$ & 1 & $2 \%$ & 14 & $35 \%$ & 20 & $50 \%$ & 40 & & \\
\hline SI & 26 & $26 \%$ & 56 & $57 \%$ & 13 & $13 \%$ & 4 & $4 \%$ & 99 & & \\
\hline BI & 27 & $44 \%$ & 21 & $43 \%$ & 13 & $21 \%$ & 1 & $2 \%$ & 62 & & \\
\hline Total & 69 & $26 \%$ & 83 & $31 \%$ & 70 & $26 \%$ & 47 & $17 \%$ & 269 & $100 \%$ & \\
\hline
\end{tabular}

The previous table(3) illustrated that in the case of high price, 57\% of (SI) tends to keep the stock, while $26 \%$ of them would go directly to buy the stock and $13 \%$ tend to sell stock. so small investors(SI) are more inclined to retain the stock more than to buy in case of price rise. On the contrary, $44 \%$ of (BI) would go directly to buy the stock and $34 \%$ of them would go to retain the stock and $21 \%$ of them go towards sales, so (BI) increase their purchases of stocks with high price gainers in the market more than sell of the shares. Meanwhile $45 \%$ of (SS) would go directly to sell the stock. While $32 \%$ wait to sell until it rise to the highest price, and $16 \%$ would go directly to buy. Therefore, when the price rise (SS) increases their sell more speed than they sell at high price. Also $35 \%$ of (BS) quickly sells, while $50 \%$ of them wait until the highest price. This is consistent with the nature of the (BS) who make their decisions up on expectations and aim to achieve the highest rate of profits. 
As it can be seen, the total traders who tended to sell (quickly or at the highest rate) were $43 \%$ of the total sample. The majority of them are speculators traders (73.5\%). While the traders who tend to keep share $31 \%$ of total sample, and the (SI) were $(67 \%)$ of them. However, traders, who tend to buy shares, are $26 \%$ of the total sample. Most of those traders $(77 \%)$ by $(\mathrm{BI})$ and $(\mathrm{SI})$, while the total of trader who tend to sell $(43 \%)$ more than those who tend to keep $(31 \%)$ or purchase $(26 \%)$. This is may adversely affect the share price in the market. Since the speculators (both SS and BS) represent $73.5 \%$ of those who tend to sell, and they make up $40 \%$ of total sample, this means that the market structure of this percentage of speculators had a negative impact on stock prices in the market.

The results proved a significant correlation between the types of traders and their reactions to price rise (Sig of Chi square =. 000) at Statistical Significance 5\%. In addition , this study test the results of independence between the variables (types of traders and their reactions) by Using statistical indicators such as coefficient of phi, Cramer, and uncertainty factor as shown in Table (4). The results confirm that there are significant correlation between the types of traders and their reactions when price rise because (p-value $=.000$ ) at the level of significance of $5 \%$, this may be due to the different objectives of each of them when they trade in the stock market.

Table (4)

The correlation between the type of traders and their reactions to price rise Symmetric Measures

\begin{tabular}{cl|c|c}
\hline \hline & & Value & Approx. Sig. \\
\hline \hline Nominal by & Phi & .683 & .000 \\
Nominal & Cramer's V & .394 & .000 \\
& Contingency Coefficient & .564 & .000 \\
\cline { 2 - 2 } N of Valid Cases & & 269 & \\
\hline \hline
\end{tabular}

a. Not assuming the null hypothesis.

b. Using the asymptotic standard error assuming the null hypothesis.

\section{2- The results in case of price reduction:}

Table (5)

Types of Traders and Their Reactions to Price Reduction

\begin{tabular}{c|c|c|c|c|c|c|c|c|c}
\hline \hline & \multicolumn{2}{|c|}{ Buy More } & \multicolumn{2}{c|}{ Sell } & \multicolumn{2}{c|}{ Keep the Stock } & \multicolumn{2}{c|}{ Total } & $\begin{array}{c}\text { Sig of Chi- } \\
\text { Square } \\
\text { Test }\end{array}$ \\
\hline Trades & Frequency & \% & Frequency & $\%$ & Frequency & \% & Frequency & $\% 100$ & $\mathbf{. 0 0 0}$ \\
\hline SS & 29 & $43 \%$ & 30 & $44 \%$ & 9 & $13 \%$ & 68 & & \\
BS & 28 & $70 \%$ & 6 & $15 \%$ & 6 & $15 \%$ & 40 & & \\
SI & 6 & $6 \%$ & 42 & $42 \%$ & 51 & $52 \%$ & 99 & & \\
BI & 11 & $18 \%$ & 18 & $29 \%$ & 33 & $53 \%$ & 62 & & \\
\hline total & 74 & $27 \%$ & 96 & $36 \%$ & 99 & $37 \%$ & 269 & $100 \%$ & \\
\hline \hline
\end{tabular}

The previous table (5) illustrates that, total traders who tended to sell $36 \%$ of the total sample. While traders who tended to buy $27 \%$, but the traders who keep the stock were $37 \%$.This shows that the proportion of traders who tend to sale in the case of a price reduction more than 
traders who tend to buy. These may adversely affect the stock price. Moreover, by analyzing the behavior of different types of traders when the price reduction the results were as follows:

1- The test found that $52 \%$ of (SI) tended directly toward keeping the stock. While $42 \%$ of them tended to sell the stock, and re-examine the market may be due to worry from the price reduction and loss ,this makes them rush towards sell, so this behaviors may have an negative impact on the stock price, especially they(SI) constitute the largest proportion in the sample. While (BI) were more conservative, where 53\% of them preference to keep the stock and $29 \%$ prefer to sell the stock, while $18 \%$ prefer to purchase. This means that (BI) tend to keep the stock more than (SI), while the greatest ratio of small investors who tend towards sell shares more than (BI) in the case of a price reduction. This result is consistent with those shown by Alzahrani and Gregoriou(2010)who examine trading behavior among small and large investors in the market. They found that large investors are more sophisticated and show higher informed trading before earnings announcements whereas smaller investors show stronger reaction to news. Moreover, small investors show a buying pattern which is consistent with times-series based earnings surprise. They are net-buyers for good news and net-sellers for bad news..

2- On the other hand, the test found that the behaviors of speculators are opposite to the behavior of small or big investors. Where $44 \%$ of (SS) tend to sell, $42 \%$ of them to purchase and 14\% tend to keep the stock. However, $70 \%$ of the (BS) tend to buy the stock, \%15 tends to sell and $15 \%$ tend to keep the stock. This means that in the case of a price reduction the behavior of the majority of big speculators tend to buy more than small speculators. While the majority of small speculators(SS) tend to sell more than big speculators(BS), this may be due to the fact that (SS) have less experience in the market or less information than big speculators so making them unable to bear the risks of buying stock in the case of price reduction.

Also Statistical analysis proved that there is significant correlation between price reduction and type of trader at Statistical Significance 5\%, since p-value $=.000$ for coefficient of Chi square, phi, Cramer, and uncertainty factor as shown in Table (6).

Table (6)

\section{Correlation Analysis between Price Reductions and Type of Trader Symmetric Measures}

\begin{tabular}{ll|c|c}
\hline \hline & & Value & Approx. Sig. \\
\hline \hline Nominal by & Phi & .561 & .000 \\
Nominal & Cramer's V & .397 & .000 \\
& Contingency Coefficient & .489 & .000 \\
N of Valid Cases & & 269 & \\
\hline \hline
\end{tabular}

c. Not assuming the null hypothesis.

d. Using the asymptotic standard error assuming the null hypothesis.

\section{Types of traders and their re-actions toward loss}

This study directed to ask traders if they faced loss when they traded in shares, their answers shown in the following Figure number (3) 


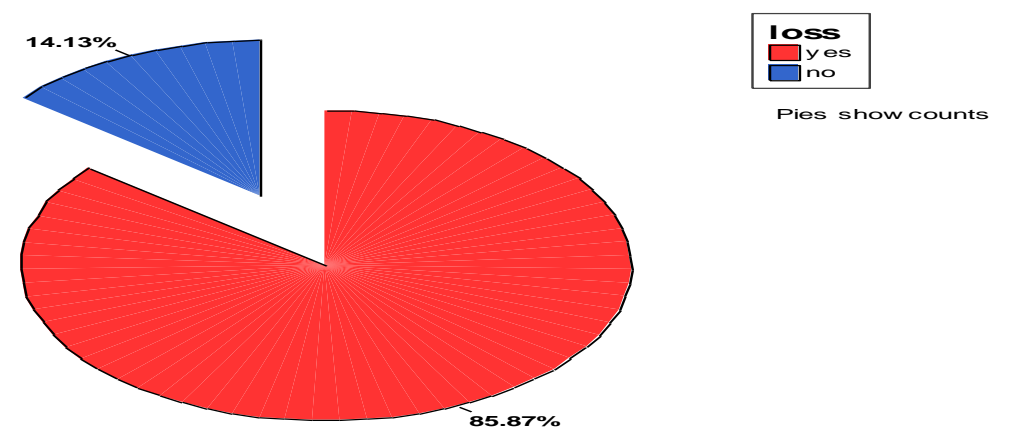

Figure (3) the ratio of traders that face loss

Traders who face loss are 230 with ratio $(86 \%)$, while traders who not face loss are 36 with ratio $(14 \%)$. This indicates to increase the ratio of traders who face loss.

\section{Third hypothesis:}

$\mathrm{H}_{0^{-}}$there is no correlation between the type of traders and their reactions when they face loss

( Sig of Chi square $>$. 05)

$\mathrm{H}_{1-}$ (Sig of Chi square <. 05)

The results from the following table (7) show four types of traders and their Reactions when they face loss as following:

Table (7)

Frequency and Percent of Traders' Reaction

When They Face Lose and Sig of Chi-Square test

\begin{tabular}{c|c|c|c|c|c|c|c|c|c|c|c}
\hline \hline & \multicolumn{2}{|c|}{$\begin{array}{c}\text { Look for } \\
\text { another share }\end{array}$} & \multicolumn{2}{|c|}{ Wait and keep } & \multicolumn{2}{c|}{$\begin{array}{c}\text { Take advice } \\
\text { from others }\end{array}$} & \multicolumn{2}{c|}{$\begin{array}{c}\text { Never trade in } \\
\text { share }\end{array}$} & \multicolumn{2}{|c|}{ Total } & $\begin{array}{c}\text { Sig of Chi- } \\
\text { Square test }\end{array}$ \\
\hline Trades & Frequency & $\%$ & Frequency & $\%$ & Frequency & $\mathbf{. 0 2 6}$ & Frequency & $\%$ & Frequency & $\mathbf{1 0 0 \%}$ & $\mathbf{. 0 2 6}$ \\
\hline \hline SS & 26 & $38 \%$ & 14 & $21 \%$ & 15 & $22 \%$ & 13 & $19 \%$ & 68 & & \\
BS & 12 & $30 \%$ & 12 & $30 \%$ & 10 & $25 \%$ & 6 & $15 \%$ & 40 & & \\
SI & 12 & $12 \%$ & 34 & $34 \%$ & 26 & $26 \%$ & 27 & $27 \%$ & 99 & & \\
BI & 4 & $7 \%$ & 35 & $57 \%$ & 13 & $21 \%$ & 10 & $16 \%$ & 62 & & \\
\hline Total & $\mathbf{5 4}$ & $\mathbf{2 0 \%}$ & $\mathbf{9 5}$ & $\mathbf{3 5 \%}$ & $\mathbf{6 4}$ & $\mathbf{2 4 \%}$ & $\mathbf{5 6}$ & $\mathbf{2 1 \%}$ & $\mathbf{2 6 9}$ & $\mathbf{1 0 0 \%}$ & \\
\hline \hline
\end{tabular}

$20 \%$ of traders were looking for other shares which distributed as follows: $48 \%$ are (SS), followed by $22.5 \%$ of (BS), $22.5 \%$ of (SI), while the percentage dropped to big investors was $6 \%$. This means that the (SS) are the most traders-oriented to search for another chance in stock market

$35 \%$ of the traders keep the stock and wait until the market and prices stabilizes, as follows: $-56 \%$ of them were (BI), followed by $34 \%$ of (SI) and $30 \%$ of (BS). While the least percentage for (SS) by $19 \%$. This means that the big investors are more traders oriented to keep the stock than others in case of facing loss. 
$24 \%$ of the traders tend to get advices from other investors who gains from their investment in shares as follows: $40 \%$ were from (SI), followed by $24 \%$ of (SS) and $20 \%$ of (BI). While the (BS)

are $16 \%$, so they are the least traders tends to others which may due their trading based on information.

$21 \%$ of the traders decide not to trade in shares and invest their funds in other investments

The results Found that the highest percentage of traders who decide not to trade in shares was (SI) by $27 \%$ followed by (SS) by $19 \%$, and the (BI) was $16 \%$, while the lowest percentage were $15 \%$ of $(\mathrm{BS})$.

Statistical analysis proved that there is significant correlation between type of trader and their reaction when they face lose, since ( Sig of Chi square $=.026<.05$ ). In addition, the following table $(8)$ illustrates that $\mathrm{p}$-value $=.000<.05$ for coefficient of phi, Cramer, and uncertainty factor at Statistical Significance $5 \%$.

Table (8)

Correlation Analysis between Price Reductions And Type of Trader Symmetric Measures

\begin{tabular}{ll|c|c}
\hline \hline & & Value & Approx. Sig. \\
\hline \hline Nominal by & Phi & .561 & .000 \\
Nominal & Cramer's V & .397 & .000 \\
& Contingency Coefficient & .489 & .000 \\
N of Valid Cases & & 269 & \\
\hline \hline
\end{tabular}

e. Not assuming the null hypothesis.

f. Using the asymptotic standard error assuming the null hypothesis.

\section{Types of traders and their behavior when they believe in specific stock:}

\section{The fourth hypothesis:}

$\mathrm{H}_{0}$ - There is no correlation between the type of traders and their reactions when they believe in specific stock (Sig of Chi square>. 05)

$\mathrm{H}_{1-}$ (Sig of Chi square <. 05)

The results from the following table (9) illustrate the four types of traders and their reactions when they believe (trust) with share which are concentrating in the following reactions. 
Table (9)

Frequency and percent of traders' reactions when they trusting With share and Sig of Chi-Square test

\begin{tabular}{|c|c|c|c|c|c|c|c|c|c|c|c|}
\hline \multirow[b]{2}{*}{ Trades } & \multicolumn{2}{|c|}{$\begin{array}{l}\text { Set all wealth } \\
\text { in stock }\end{array}$} & \multicolumn{2}{|c|}{$\begin{array}{l}\text { Set most of } \\
\text { wealth }\end{array}$} & \multicolumn{2}{|c|}{$\begin{array}{l}\text { Not sell in } \\
\text { suitable time }\end{array}$} & \multicolumn{2}{|c|}{$\begin{array}{l}\text { Looking for } \\
\text { alternative } \\
\text { stock. }\end{array}$} & \multicolumn{2}{|c|}{ Total } & \multirow{2}{*}{$\begin{array}{r}\begin{array}{c}\text { Sig of } \\
\text { Chi- } \\
\text { Square } \\
\text { test }\end{array} \\
.486\end{array}$} \\
\hline & Frequency & $\%$ & Frequency & $\%$ & Frequency & $\%$ & Frequency & $\%$ & Frequency & $100 \%$ & \\
\hline$\overline{S S}$ & 6 & $9 \%$ & 22 & $32 \%$ & 24 & $35 \%$ & 16 & $24 \%$ & 68 & & \\
\hline BS & 3 & $8 \%$ & 16 & $40 \%$ & 16 & $40 \%$ & 5 & $12 \%$ & 40 & & \\
\hline SI & 6 & $6 \%$ & 36 & $36 \%$ & 48 & $48 \%$ & 9 & $9 \%$ & 99 & & \\
\hline BI & 3 & $5 \%$ & 27 & $44 \%$ & 23 & $37 \%$ & 9 & $14 \%$ & 62 & & \\
\hline Total & 18 & $7 \%$ & 101 & $35 \%$ & 111 & $41 \%$ & 39 & $14 \%$ & 269 & $100 \%$ & \\
\hline
\end{tabular}

The results prove that:

First, 37.5\% of traders set the most of their wealth in the share which they believe in it, this percent distributed as follows

The (SI) represent 36\%, (BI) represents $27 \%$, (SS) represent $22 \%$ and $16 \%$ were (BS). This means that the (SI) were the largest percentage of traders, and they set the most of their wealth in the share, which they believe in. This may be due to the decrease in their funds and could be apply on (SS), but they were relatively more careful than (SI) because of their trading is short-term and high-risk transactions.

Second, $41 \%$ of traders not sell in suitable time, this percent distributed as follows:

(SI) represent $43 \%$, then (SS) by $22 \%$, then (BI) by $21 \%$, while the least percent was for (BS) $14 \%$ which is related to the nature of speculators who make their decisions on the information. follows:

Third, $15 \%$ of traders search about alternative share, this percent distributed as

The greatest part of this percent is for small speculators, which represent $41 \%$, which is consistent with the nature of their dealings, are based on expectations and short-term. But the percentage of small investors $23 \%$, then big investors by $23 \%$, while the lowest was for the large speculators is about $13 \%$ which proves that they are more careful about their decisions and more accurate than other traders because their transactions are often based on the information.

The results prove that there is no significant relationship between the type of trader and their behavior when they believe in specific share, since p-value $=.486>.05$ at the level of significance 5\% for Chi square, , phi, Cramer, and uncertainty factor, which appears in the following table (10): 


\section{Table (10) \\ Correlation between the types of Traders And Their Behavior When They Believe in Specific Stock Symmetric Measures}

\begin{tabular}{ll|c|c}
\hline \hline & & Value & Approx. Sig. \\
\hline \hline Nominal by & Phi & .207 & .486 \\
Nominal & Cramer's V & .119 & .486 \\
& Contingency Coefficient & .203 & .486 \\
\multirow{2}{*}{ N of Valid Cases } & & 269 & \\
\hline \hline
\end{tabular}

g. Not assuming the null hypothesis.

h. Using the asymptotic standard error assuming the null hypothesis.

\section{Conclusion}

This study analyzes Trading Behavior of four types of traders in Saudi stock market. Traders classified into big versus small traders and Speculative versus Investor, the sample has 268 traders from all different business sectors. The results described that $60 \%$ of the total traders in the sample are investors. on the other hand, the percentage of speculators are $40 \%$, this help to analyze and interpret the impact of this distribution relative on the share trading in the Saudi stock market, and through the results of hypotheses test that analysis behavior and reactions of different types of traders in this market.

The results shown that there are significant differences between their reactions towards the share price rise or reduction in the market, as well as their reactions towards facing loss (the sale price less than purchase price). Meanwhile there is no significant difference between their behavior when they believe (trust) of stock and expect to achieve more of it. When the price rise traders who tend to sale $(43 \%)$ more than those who tend to retain $(31 \%)$ or purchase (26\%). These results may be adversely affecting the share price in the market. Especially speculators are representing $73.5 \%$ of those who tend to sale and they make up $40 \%$ of the sample. This means that the market structure of this percentage of speculators (40\%) had a negative impact on stock prices in the market. Whoever in the case of price reduction, the total traders who tended to sale $36 \%$, while traders who tended to buy $27 \%$, but the traders who retain the stock were $37 \%$. This mean that traders who tend to sale in the case of a price reduction more than traders do who tend to buy, this may cause adversely affect on share price.

In addition, the results indicate to increase the ratio of traders who face loss. Since traders that face loss is 230 traders with ratio ( $86 \%$ ), while the number of traders that not face loss is 36 traders with ratio (14\%). There are differences between traders reactions when they were facing loss, since the results shown that (SS) are the most traders-oriented to search for another chance in stock market. While the big investors are, more traders oriented to keep the stock than others in case of facing loss. Also the big speculators (BS) were the least traders who tend to get advices from other investors that may be due to their trading which based on information. The results Found that the highest percentage of traders who face loss decided not to trade in shares were (SI).

The results prove that there is no significant relationship between the types of traders and 
their behavior when they believe in specific stock. Analysis of behavior and reactions of different types of traders shown that, the (SI) were the largest percentage of traders who set the most of their wealth in the share, which they believe in. This may be due to the decrease in their funds and could be applying on (SS) but they were relatively more careful than small investors because of their trading are short-term and high-risk transactions, $41 \%$ of traders not sell in suitable time. The least percent was for (BS) $14 \%$ that related to the nature of speculators who make their decisions on the information. While $15 \%$ of traders searched about alternative share. Since the lowest percent was for the large speculators (13\%), this proves that they are more careful about their decisions and more accurate than other traders are, because their transactions are often based on the information.

1- Stock market administration should insure the market information transparency to reduce the gap between the informed traders (speculators) and uninformed traders to avoid any illegal profit of some traders versus the rest of other traders who were not accessibility to required information.

2- 2-Also to raise the level of market efficiency requires awareness of the traders how use the information to deal sufficiently in stock market. It is necessary to do some further studies to rationalize the decisions of traders in the market so that they can take advantage of the available information and avoid attempts by speculators to maximize their profits at the expense of other investors. 


\section{REFERENCES}

- Jalal, Alsiaad and Mostafa Jalal. (1990). Introduction to statistical Sampling Methods. Jeddah: Misbah Library, pp 110-121

- Abdullah, Alsubaiea and Najandb Mohammad. (2009). "Trading Volume, Time-varying Conditional Volatility, and a Symmetric Volatility Spill Over in the Saudi Stock Market" Journal of Multinational Financial Management, 19, 139-159.

- Alzahrani A., Ahmed and Gregoriou Andros. (2010). What Happens Around Earning Announcements? An Investigation of Information Asymmetry and Trading Activity in the Saudi Market Economics and Finance. Working Paper Series, Department of Economics and Finance, Brunel University, West London.

- Benjamin, Ayers; Li Zhen and Yeung Eric. (2011). "Investor Trading and the Post-earnings Announcement Drift", The Accounting Review, 86, 385-416.

- Barclay, M. J. and J. B. Warner. (1993). "Stealth Trading and Volatility: Which Trades Move Prices?", Journal of Financial Economics, 34, 281-305.

- Brown, A. Philip and Others. (2002). "The Influence of Cultural Factors on Price Clustering: Evidence from Asia-Pacific Stock Markets", Pacific-Basin Finance Journal, 10, 307- 332.

- Burks Jeffrey. (2011). “Are Investors Confused by Restatements After Sarbanes-Oxley?”, The Accounting Review, Sarasota, 86, 507-539.

- Caginalp, G. and B. Ilieva. (2008). "The Dynamics of Trader Motivations in Asset Bubbles" Journal of Economic Behavior \& Organization, 66, 641-656.

- Carcano, G.; P. Falbo and S. Stefani. (2005). "Speculative Trading in Mean Reverting Markets" European Journal of Operational Research, 163, 132-144.

- Kent, Daniel; Hirsh Leiferc David and Teoh Siew. (2002). "Investor Psychology in Capital Markets: Evidence and Policy Implications”, Journal of Monetary Economics, 49, 139-209.

- Ghassan, Dibeh. (2005). Speculative Dynamics in a Time-delay Model of Asset Prices. Physical A355 , 199-208

- Easley, D. and M. O'Hara. (1987). "Price, Trade Size, and Information in Securities Markets", Journal of Financial Economics, 19, 69-90.

- Mun, Fong Wai. (2009). "Speculative Trading and Stock Returns: A Stochastic Dominance Analysis of the Chinese Share Market", Journal of International Financial, 19, 712-727.

- Hales Jeffrey. (2009). "Are Investors Really Willing to Agree to Disagree? An Experimental Investigation of How Disagreement and Attention to Disagreement Affect Trading Behavior", Organizational Behavior and Human Decision Processes, 108, 230-241.

- Peter, Heemeijer and Others. (2009). "Price Stability and Volatility in Markets with Positive and Negative Expectations Feedback: An Experimental Investigation", Journal of Economic Dynamics \& Control, 33 1052-1072.

- Kaustia, Markku and Sami Torstila. (2011). Stock Market Aversion? Political Preferences and Stock Market Participation”, Journal of Financial Economics, 100, 98-112.

- Lee, Y.; X. Jiang and C. Indro. (2002). "Stock Market Volatility, Excess Returns, and the Role of Investor Sentiment", Journal of Banking \& Finance, 26, 2277-2299. 
- Lee, Y. and Others. (1999). "Trading Patterns of Big Versus Small Players in an Emerging Market: An Empirical Analysis", Journal of Banking \& Finance, 23, 701-725.

- Kumar, Narayan Paresh. (2011). "Share Price Clustering in MEXICO", International Review of Financial Analysis, 20, 113-119.

- Mark, Nelson, and Others. (2001). "The Effect of Information Strength and Weight on Behavior in Financial Markets", Organizational Behavior and Human Decision Processes, 86, 168-196.

- Lilian, N. G. and Wu Fei. (2007). The Trading Behavior of Institutions and Individuals in Chinese Equity Markets", Journal of Banking \& Finance, 31, 2695-2710.

- Norusis, J. Marija. (2003). SPSS 12 Statistical Procedures Companion. Prentice Hall, 143-147.

- Odean, T. (1998). “Are Investors Reluctant to Realize Their Loses?”, Journal of Finance, 53, 1775-1798.

- Vitale, Paolo. (2000). "Speculative Noise Trading and Manipulation in the Foreign Exchange Market”, Journal of International Money and Finance, 19, 689-712.

- Sirri, E. R. and P. Tufano. (1998). "Costly Search and Mutual Fund Flows", Journal of Finance, $53,1589-1622$. 


\section{Questioner:}

Q. 1 Which of the following objectives you want to achieve?

- Stable and continue gains.

- High and quickly gains.

Q.2 Are you keeping the stock for a Short period until the expected event-taking place?

- Yes - No

Q.3 How many share you invest?

- Less than 10,000 shares

- Over than 10,000 shares

Q.4 What you will do when stock's price tend to rise?

- Buy more.

- Sell stock quickly

- Keep the stock (no action)

- Wait until highest price before it tend to be down

Q.5 What you will do when stock's price reduction?

- Buy more.

- Sell stock quickly

- Keep the stock

Q.6 Do you have experience loss when investing in shares? Yes No

Q.7 If your answer is yes, what is at your disposal?

- Quickly search for other shares to compensate for the loss

- Wait until the market and prices stabilize.

- Taking the advice of another investor made gains in the stock market.

- Not to trade in shares and invest their funds in other investments

Q.8 If you trust in specific stock and believe to achieve further gains, which action from the flowing you will do:

- Invest all your wealth in this stock.

- Concentrate the great part of your wealth in this stock

- Do not sell this stock in suitable time before the price down so you do not control the loss.

- Looking for alternative stock. 